\title{
Boxwood Dieback Caused By Colletotrichum theobromicola: A Diagnostic Guide
}

Raghuwinder Singh ${ }^{\dagger}$ and Vinson P. Doyle, Department of Plant Pathology and Crop Physiology, Louisiana State University Agricultural Center, Baton Rouge 70803

Accepted for publication 18 July 2017.

Boxwood (Buxus spp.) is a popular perennial landscape shrub in the United States grown for its vibrant green color and evergreen growth. Several important plant diseases including boxwood blight, Macrophoma blight, Phytophthora root rot, Volutella blight, and plant pathogenic nematodes including lesion, root-knot, and spiral are known to occur on boxwood. In 2015, a new disease of boxwood called boxwood dieback was identified in Louisiana and is the first known report in the United States (Singh and Ratcliff 2016; Singh et al. 2015). Boxwood dieback is a stem/shoot disease caused by a fungal pathogen, Colletotrichum theobromicola. Previous reports have shown an association between Colletotrichum spp. and Buxus spp. (Crouch 2012; Farr and Rossman 2016; Holcomb 1967).

Host: English boxwood (Buxus sempervirens), Japanese boxwood (Buxus microphylla var. japonica), and Korean boxwood (Buxus microphylla var. koreana)

Disease: Boxwood dieback

Pathogen: Colletotrichum theobromicola Delacr. 1905 (phylum Ascomycota, order Phyllachorales) = Colletotrichum fragariae A.N. Brooks $1931=$ Colletotrichum gloeosporioides f. stylosanthis Munaut 2002

\section{Taxonomy}

Weir et al. (2012) reviewed the taxonomy of the fungus Colletotrichum gloeosporioides, treating it as a complex of 22 different species along with a subspecies and potentially one forma specialis. See also Farr and Rossman (2016).

\section{Symptoms and Signs}

Boxwood dieback is characterized by random dieback of twigs. Foliage turns light tan and tends to remain attached to the affected branches (Fig. 1). Symptomatic plants have a healthy crown and root system (Fig. 2). The infection causes bright black discoloration of the stem under the bark (Fig. 3), which extends to the center of the woody tissue and can be observed in a cross section of the symptomatic twigs (Fig. 4). This bright black discoloration is present all along the infected twigs and differs from discoloration of the crown region caused by Phytophthora root rot. Incubation of small, newly-infected boxwood twigs in a moist chamber for two weeks produces black acervuli on the bark with black setae (Fig. 5) and sticky, salmoncolored conidia (Fig. 6). Similar symptoms on boxwoods have been

${ }^{\dagger}$ Corresponding author. E-mail: rsingh@agcenter.lsu.edu

(C) 2017 The American Phytopathological Society observed in landscape plantings for several years, but may have been incorrectly attributed to Phytophthora root rot or Volutella blight.

\section{Host Range}

In the United States, boxwood dieback has been detected and identified in a number of states but has been reported to date only

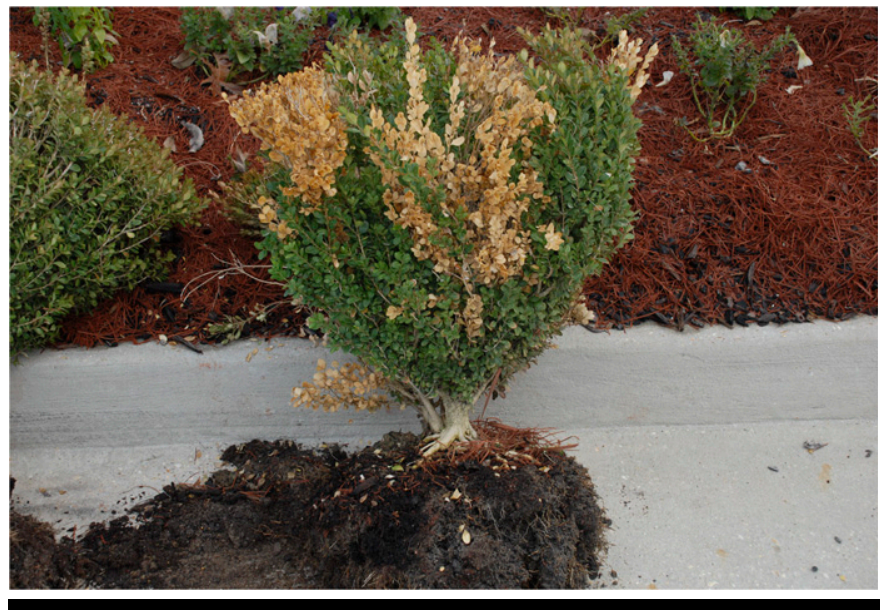

\section{FIGURE 1}

Random dieback of twigs with light tan-colored foliage caused by boxwood dieback.

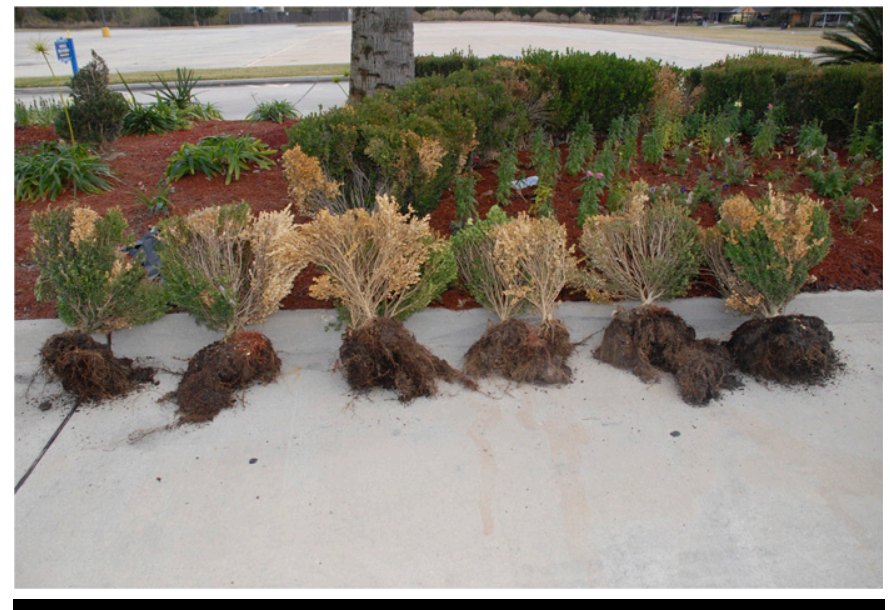

FIGURE 2

Roots and crowns of boxwood infected by C. theobromicola appear healthy. 


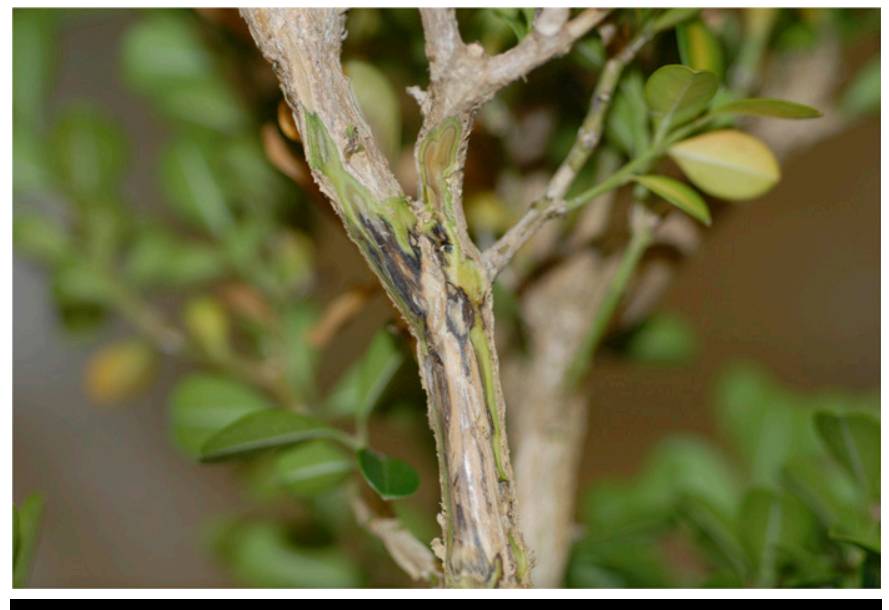

FIGURE 3

Bright black discoloration of the stem under the bark caused by $C$. theobromicola.

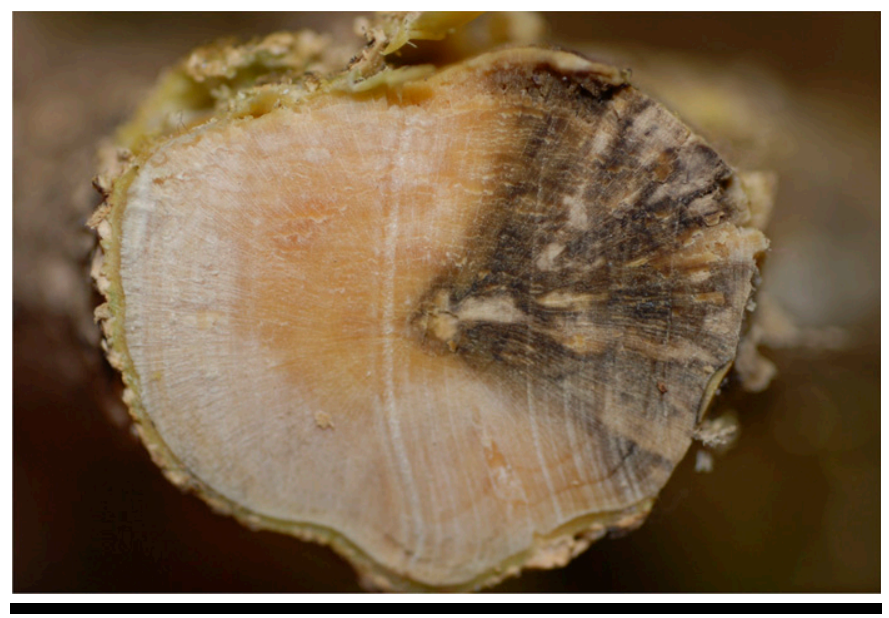

FIGURE 4

Cross section of a symptomatic boxwood twig infected with boxwood dieback showing discoloration extending to the center of the woody tissue.

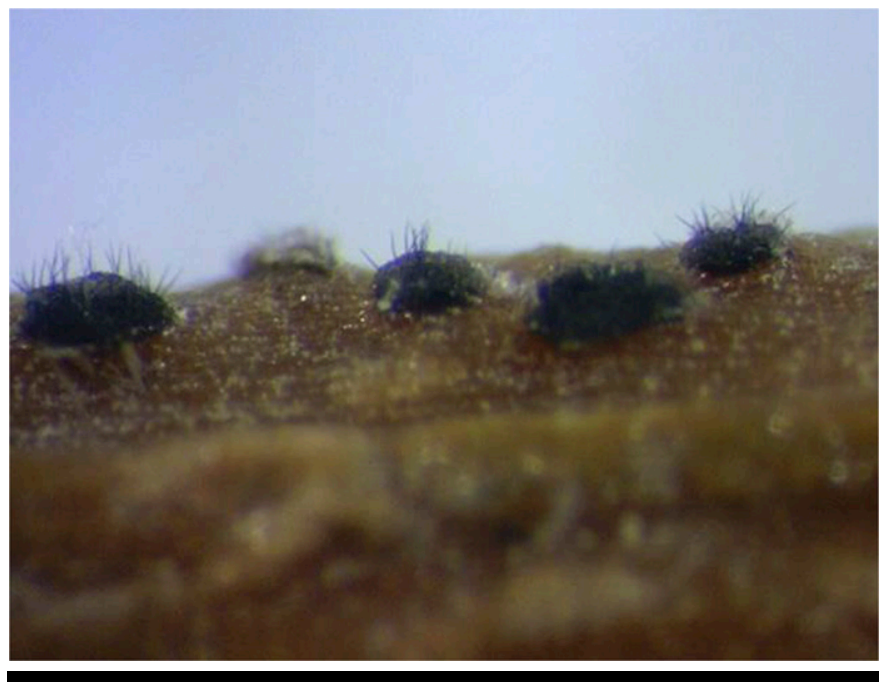

FIGURE 5

Acervuli of $C$. theobromicola with black setae produced on bark of infected boxwood twigs in a moist chamber. from Louisiana, North Carolina, New York, South Carolina, and Virginia (Singh et al. 2015).

\section{Geographic Distribution}

Complete information on the susceptibility of boxwood cultivars to $C$. theobromicola is not available. However, English, Japanese, and Korean cultivars of boxwood have been found to be very susceptible (personal observation).

\section{Pathogen Isolation}

Colletotrichum theobromicola can be easily isolated from young symptomatic tissue, such as small twigs. Surface-disinfest 1- to 2inch pieces of symptomatic tissue with $10 \%$ bleach for 3 min. Rinse the tissue with sterile tap water and blot dry. Remove bark aseptically and cut the tissue into thin, circular discs. Surface-disinfested thin slices taken from the transition zone between discolored and healthy tissue of infected twigs may also be used for isolation. Plate disc or thin slices on 1/4-strength potato dextrose agar (PDA) $(9.75 \mathrm{~g} \mathrm{PDA}+11.25 \mathrm{~g}$ agar/liter) and incubate in an incubator at $28^{\circ} \mathrm{C}$ (Fig. 7).

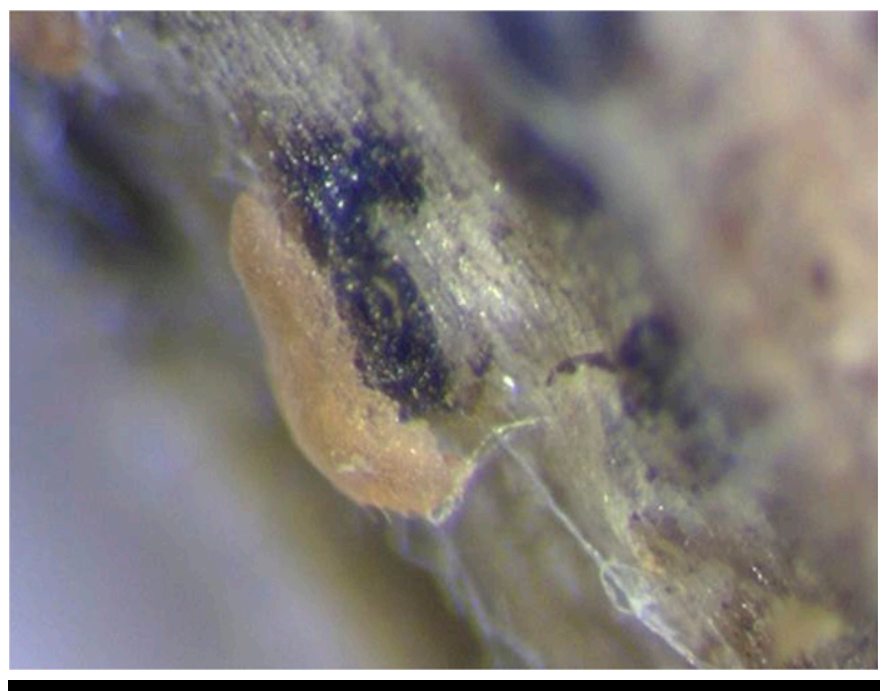

FIGURE 6

Salmon-colored, sticky conidia produced on infected boxwood twigs in a moist chamber.

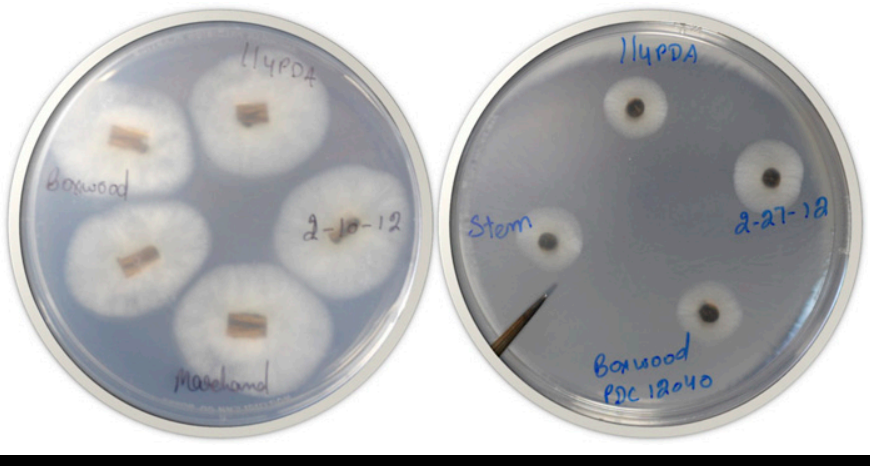

FIGURE 7

Colonies of $C$. theobromicola isolated from thin slices (left) and discs (right) of infected boxwood twigs plated on to 1/4-strength potato dextrose agar. 


\section{Pathogen Identification}

Ten-day-old colonies of $C$. theobromicola on potato dextrose agar are gray to dark black with salmon-colored conidiomata (Fig. 8 ). The production of aerial mycelia has been observed in a few isolates from Louisiana. Conidia are single-celled, hyaline, cylindrical with rounded ends and measure 15 to $20 \mu \mathrm{m} \times 3.75$ to $6.25 \mu \mathrm{m}$ (Fig. 9). Setae are generally not observed in cultures, but become abundant in 7 to 10 days after conidiomata are touched with a dissecting needle. Setae are simple, light brown, with 2 to 4 septa, and measure 70 to $105 \mu \mathrm{m} \times 2.5$ to $5.0 \mu \mathrm{m}$ (Fig. 10). No perithecia have been observed in culture. Appressoria are abundant in three- to four-week-old cultures (Fig. 11).

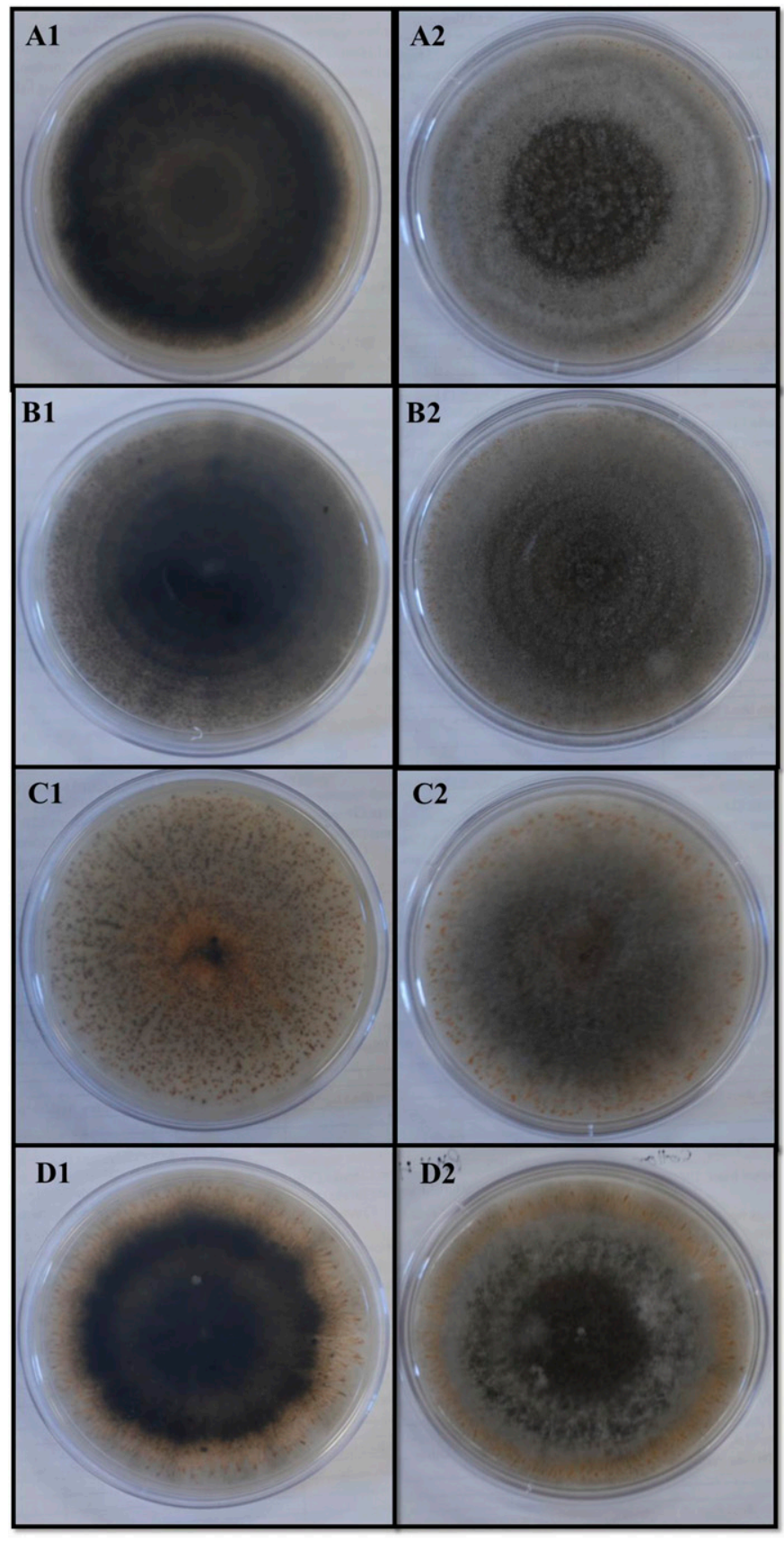

FIGURE 8

Cultures of $C$. theobromicola on potato dextrose agar ( $1=$ lower surface, $2=$ upper surface) at 10 days: (A) Louisiana isolate 2011; (B) Louisiana isolate 2012; (C) South Carolina isolate 2014; and (D) Virginia isolate 2012.
Colletotrichum theobromicola belongs to the fungal phylum Ascomycota and the family Glomerellaceae. The genus Colletotrichum is divided into several complexes of closely related species that are difficult or impossible to distinguish solely on the basis of morphological characters. Colletotrichum theobromicola is a member of the C. gloeosporioides species complex. However, based on multilocus phylogenetic studies, $C$. theobromicola forms a monophyletic clade and has been accepted as a distinct species within the complex (Weir et al. 2012).

At present, molecular identification of $C$. theobromicola can be achieved by amplifying three genes: actin (ACT), chitin synthase (CHS1), and the nuclear ribosomal internal transcribed spacers (ITS) (see Table 1 for specific details). Other loci that can be used to identify $C$. theobromicola include glyceraldehyde 3-phosphate dehydrogenase (GAPDH), calmodulin, manganese-superoxide dismutase (SOD2), $\beta$-tubulin 2 (TUB2), glutamine synthetase (GS) (Weir et al. 2012), DNA lyase (APN2), and the intergenic region between DNA lyase and the mating type locus (MAT1-2) (Rojas et al. 2010, Doyle et al. 2013).

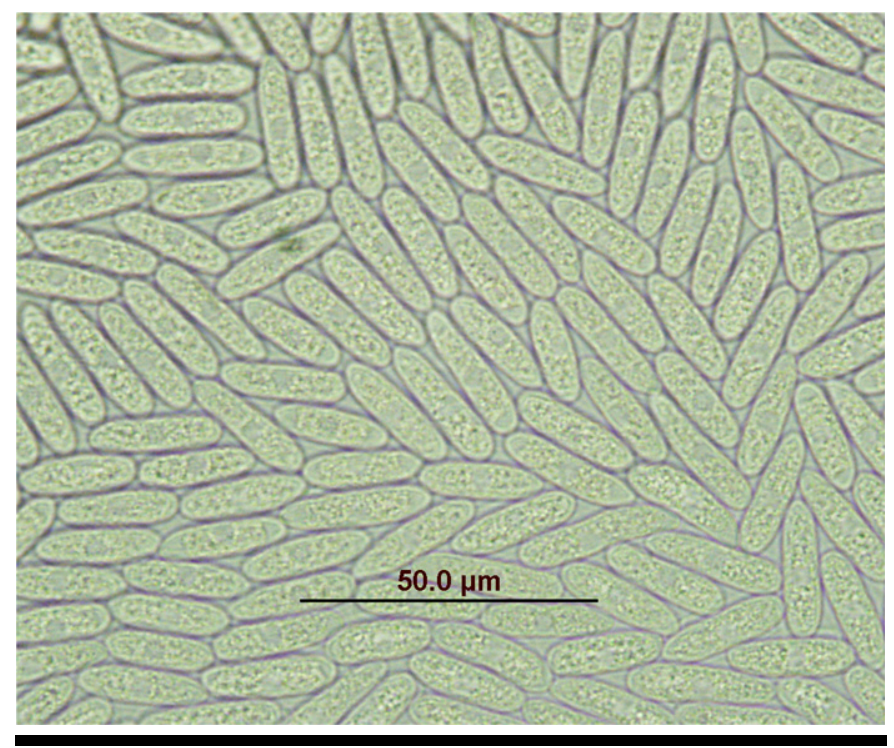

\section{FIGURE 9}

Conidia of $C$. theobromicola grown on 1/4-strength potato dextrose agar.

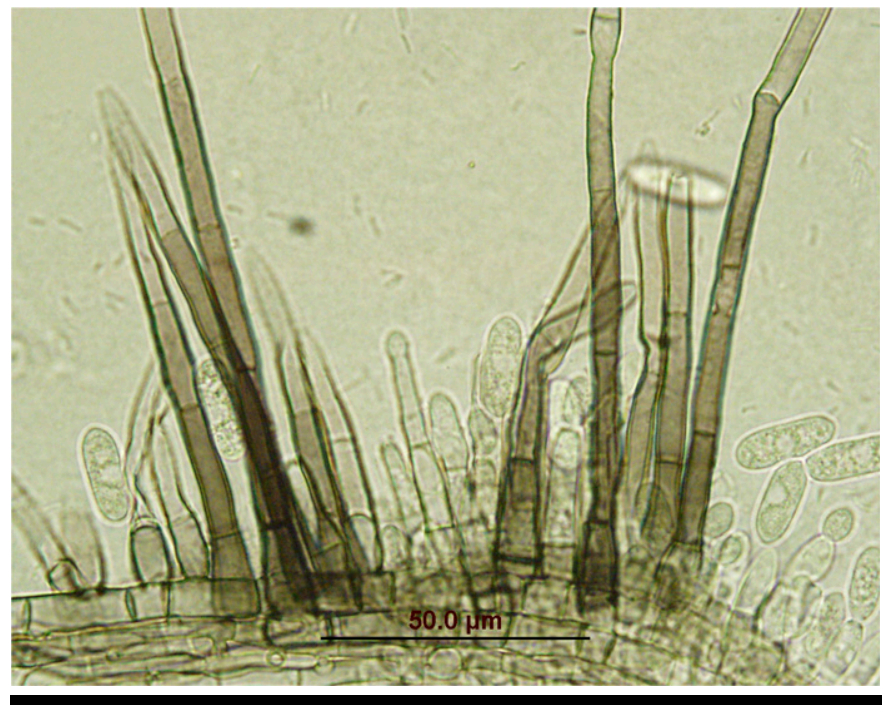

FIGURE 10

Setae of $C$. theobromicola grown on 1/4-strength potato dextrose agar. 
Sequence data representing three isolates of $C$. theobromicola from boxwood for actin (GenBank Accession Nos. KP642638, KP642639, and KP642640), chitin-synthase (KP642641, KP642642, and KP642643) and the internal transcribed spacer (KM505031, KM505032, and KM505033) are available for comparison in GenBank. The ITS sequences of four isolates from Louisiana, South

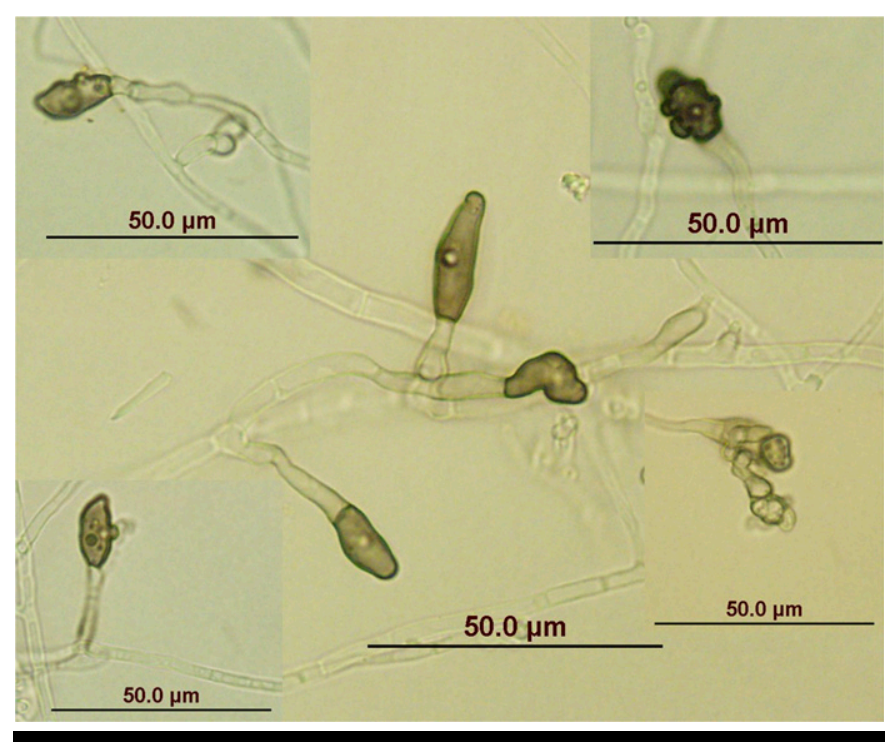

FIGURE 11

Appressoria of C. theobromicola grown on 1/4-strength potato dextrose agar.
Carolina, and Virginia consisted a string of eight C's in the ITS region (Fig. 12), which is considered a characteristic identification feature for $C$. theobromicola according to Weir et al. 2012.

\section{Pathogenicity Tests}

Single spore cultures of $C$. theobromicola can be grown on 1/4strength PDA for seven days at $28^{\circ} \mathrm{C}$ to produce inoculum. In order to inoculate healthy plants, create a $25-\mathrm{mm} \times 5-\mathrm{mm}$ wound on the stem and pull the bark back to expose woody tissue. Do not completely remove the bark from the stem. Cut an agar-culture strip of the same dimensions as the stem wound and place it between the wood and bark. The top surface of the culture strip (surface with conidiomata and conidia) must face the woody tissue. Secure the bark flap to the back of the agar strip and wrap the inoculated area in Parafilm. Inoculate the negative control plants as described above with an agar strip. Maintain all plants in a greenhouse at 26 to $30^{\circ} \mathrm{C}$ and $85 \%$ relative humidity.

\section{Disease Epidemiology}

Boxwood dieback is a foliar disease that has been detected in boxwood liners (Fig. 13). The disease is thought to be introduced to new locations via infected liners. Disease spread from plant to plant is accomplished by poor pruning practices, and by the dispersal of conidia via rain or irrigation water. Although environmental conditions affecting disease development are not known, symptoms will develop after three months when artificially inoculated boxwood plants are maintained in a greenhouse at 26 to $30^{\circ} \mathrm{C}$ and $85 \%$ relative humidity (Fig. 14).

$\begin{array}{cllc} & & & \text { TABLE } 1 \\ \text { Genes, primers, PCR parameters, and product size to identify C. theobromicola isolated from Buxus spp. }\end{array}$

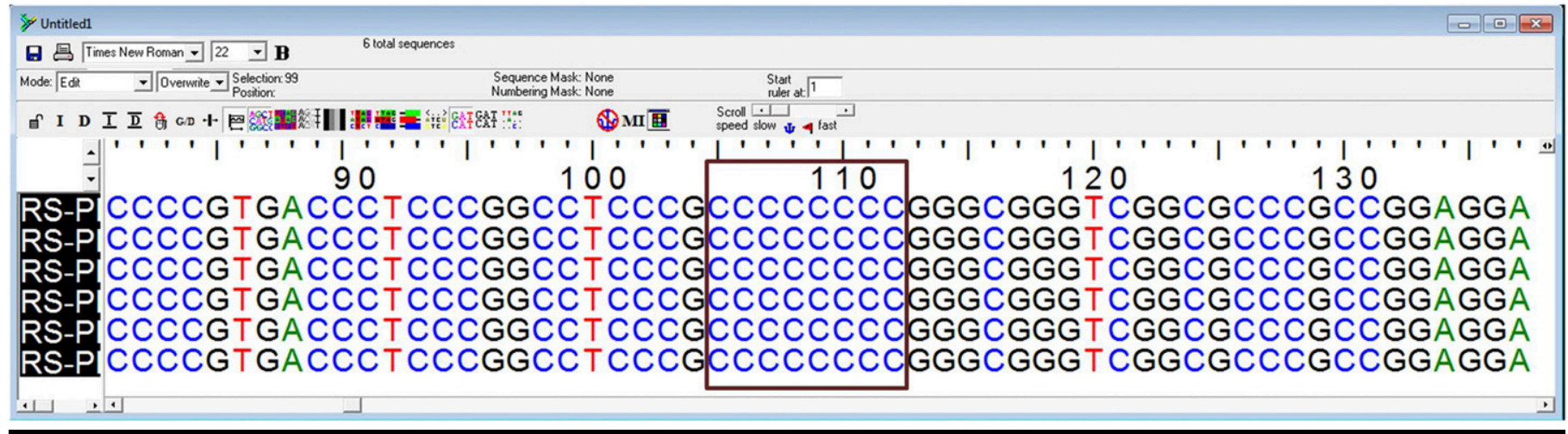

FIGURE 12

Screenshot of internal transcribed spacer sequence alignments of three $C$. theobromicola isolates showing string of eight C's in the ITS region. 


\section{Disease Management}

Since boxwood dieback is a recently discovered disease, rapid diagnostic tools and effective control measures such as fungicides are currently limited. Therefore, landscapers, nurserymen, and homeowners should follow good cultural practices and create an environment that is most likely to decrease the spread and development of boxwood dieback. Since removing dead and dying twigs from plants infected by the pathogen is not known to control this disease, all symptomatic plants in the landscape should be removed and destroyed. Surface disinfestation of pruning and cutting tools is important to reduce its spread. Avoiding unnecessary plant injury may also help avoid any potential infection by the pathogen.

Nursery owners should closely monitor liners and potted boxwoods for symptoms of boxwood dieback. Suspected plants must be immediately isolated from healthy plants. Disease management strategies practiced for managing Phytophthora root rot will not provide management of boxwood dieback. Laboratory testing is required to confirm boxwood dieback because it can easily be

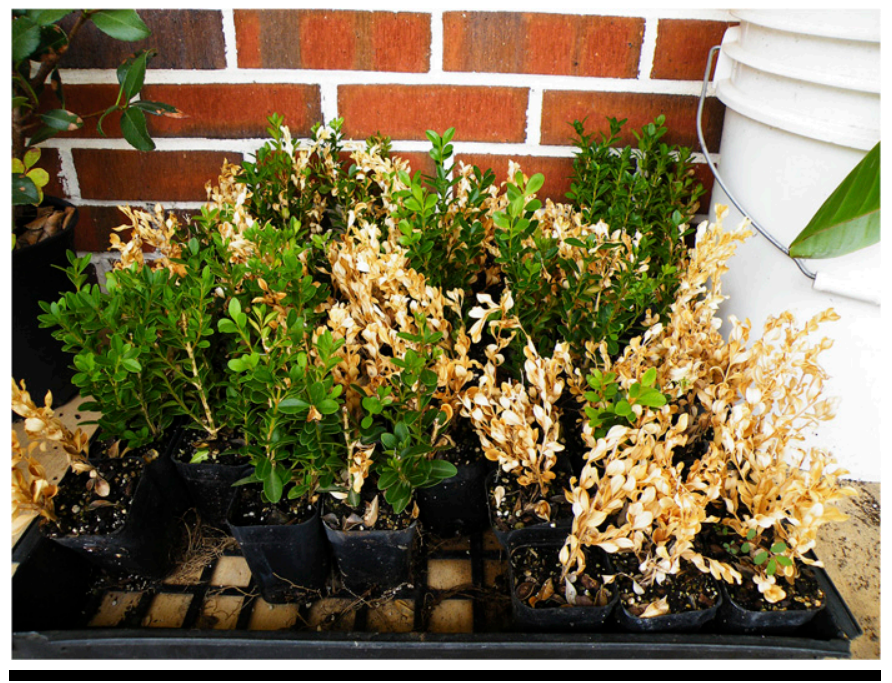

FIGURE 13

Boxwood liners infected with C. theobromicola.

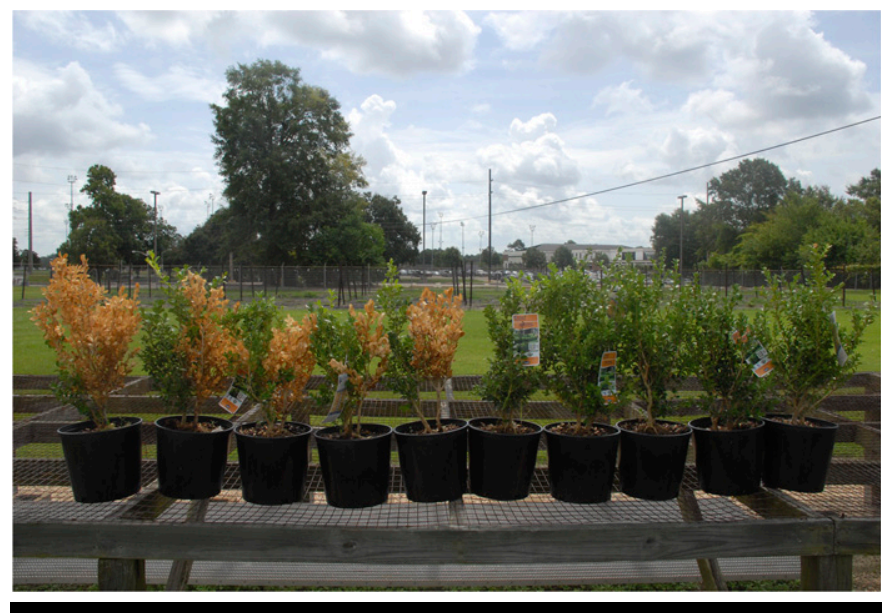

FIGURE 14

Japanese boxwood inoculated with C. theobromicola showing symptoms of dieback (left five plants, inoculated; right five plants, control). misdiagnosed as Phytophthora root rot (Figs. 15 and 16) or Volutella blight (Fig. 17). Other biotic and abiotic agents that may cause similar symptoms to boxwood dieback include boxwood blight (Calonectria pseudonaviculata) (Fig. 18), Macrophoma blight (Fig. 19), cold injury (Fig. 20), high temperature injury (Fig. 21), and herbicide injury (Fig. 22).

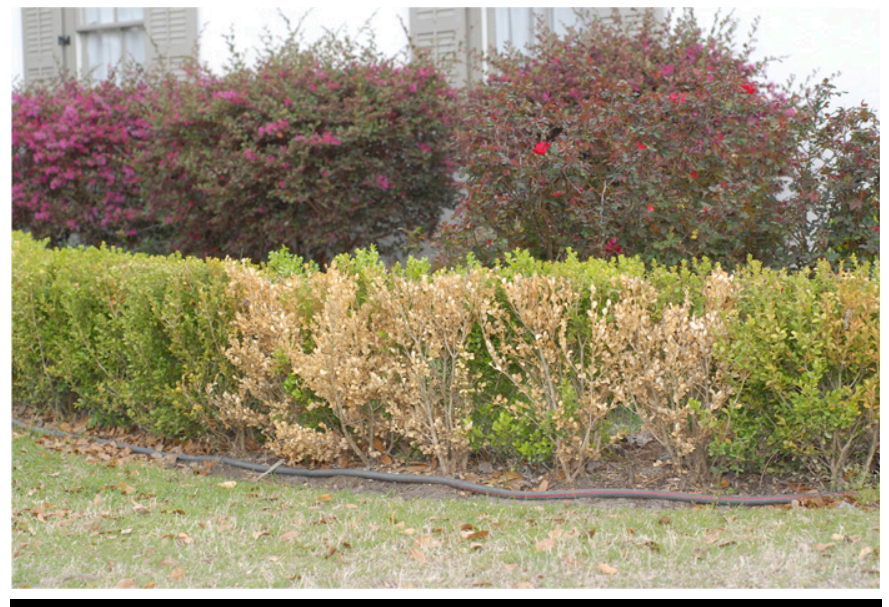

FIGURE 15

Foliar symptoms of boxwood infected with Phytophthora root rot.

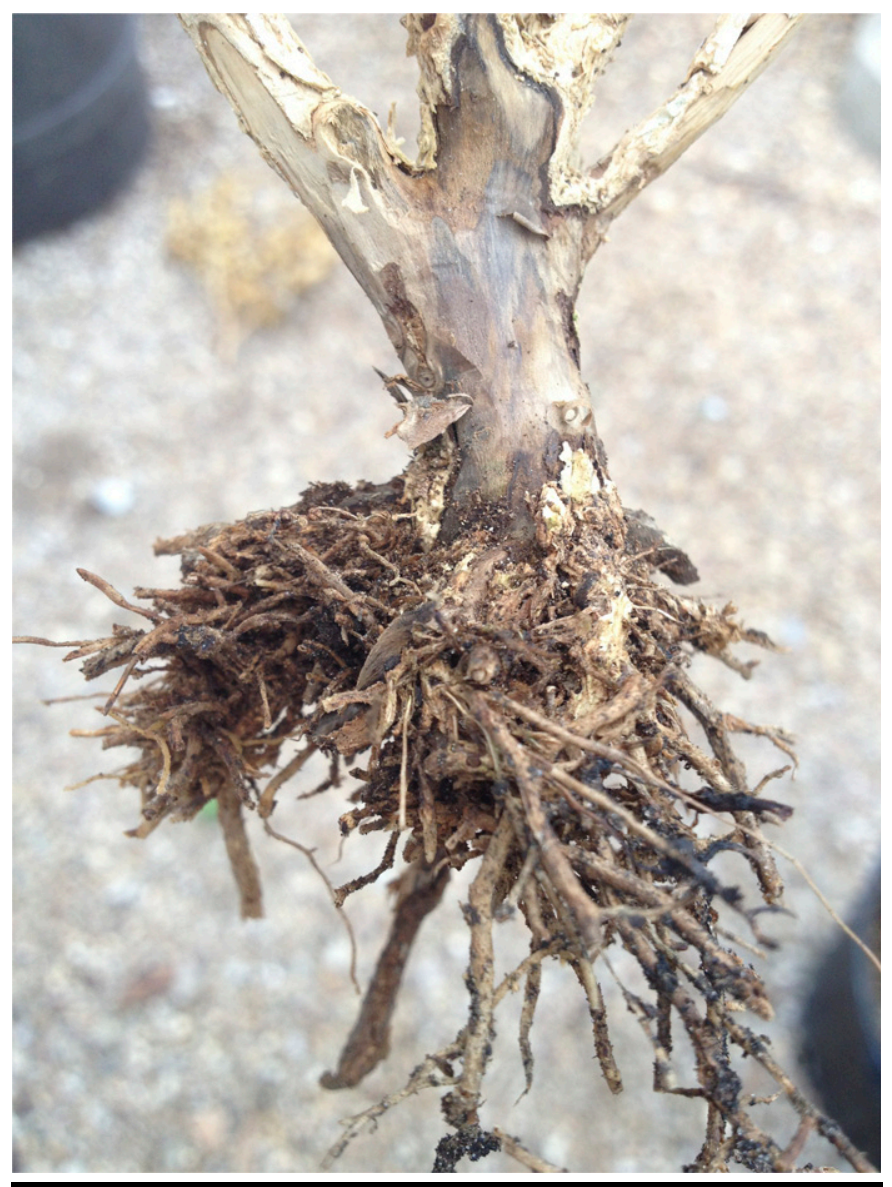

FIGURE 16

Root and crown rot symptoms of boxwood caused by Phytophthora root rot. 


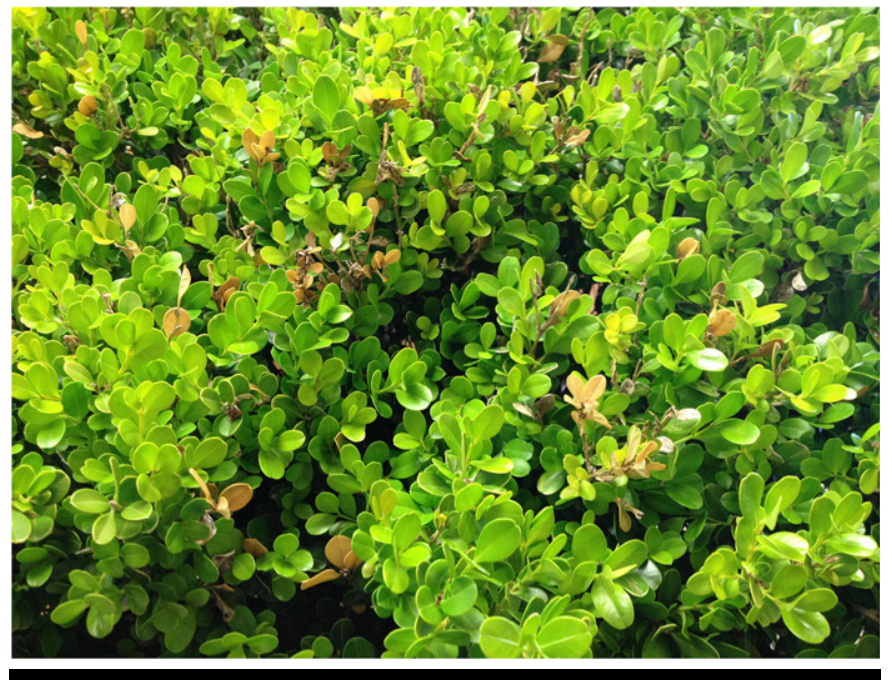

FIGURE 17

Boxwood infected with Volutella blight.

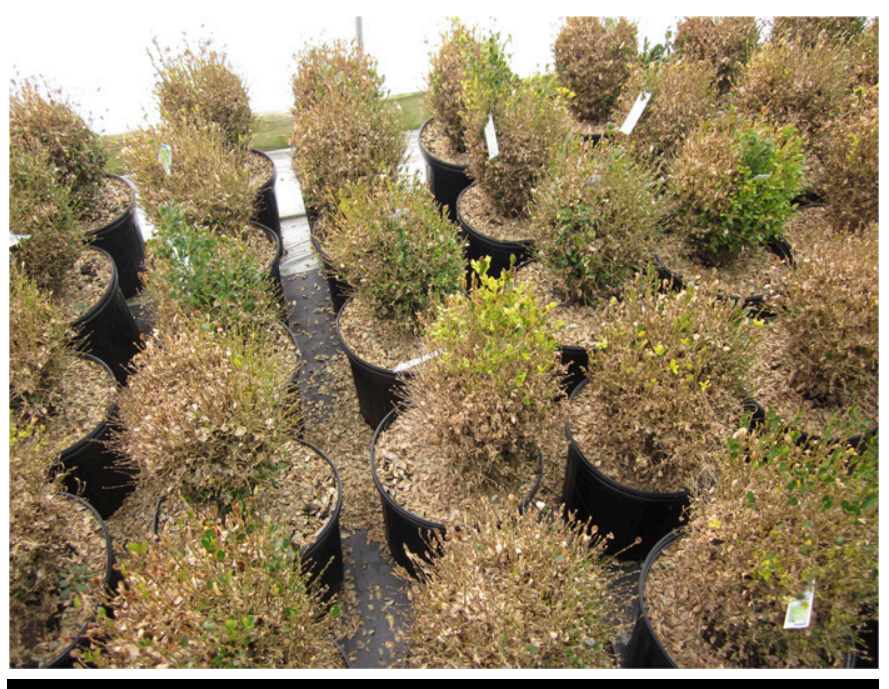

FIGURE 18

Boxwood blight caused by Calonectria pseudonaviculata.

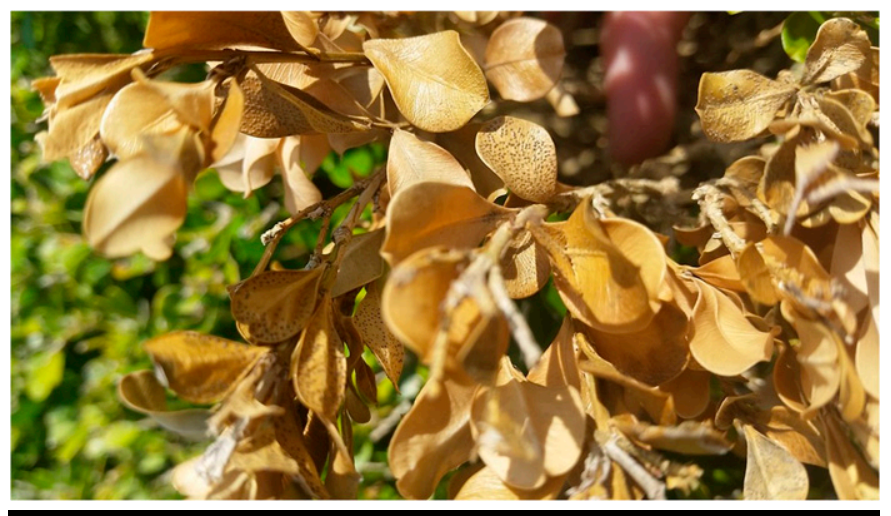

FIGURE 19

Boxwood infected with Macrophoma blight.

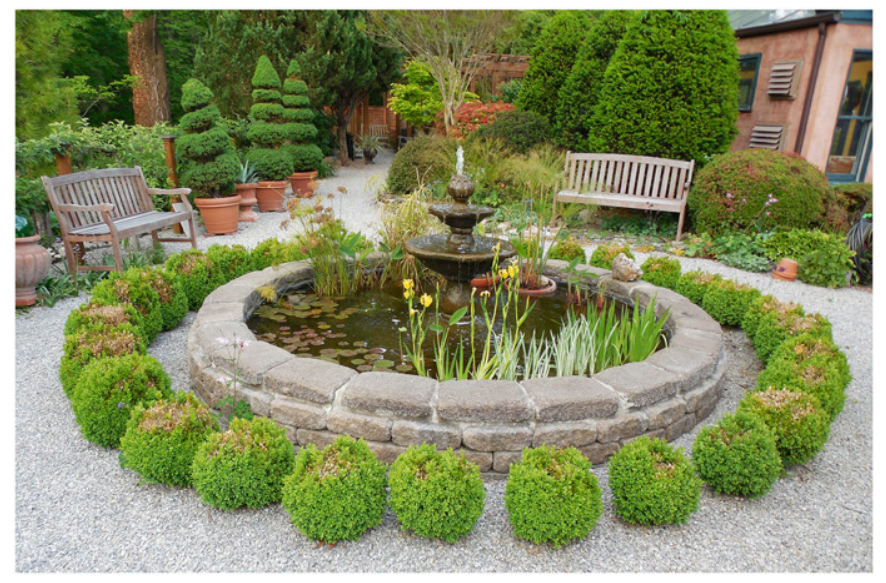

FIGURE 20

Foliar symptoms caused by cold injury.

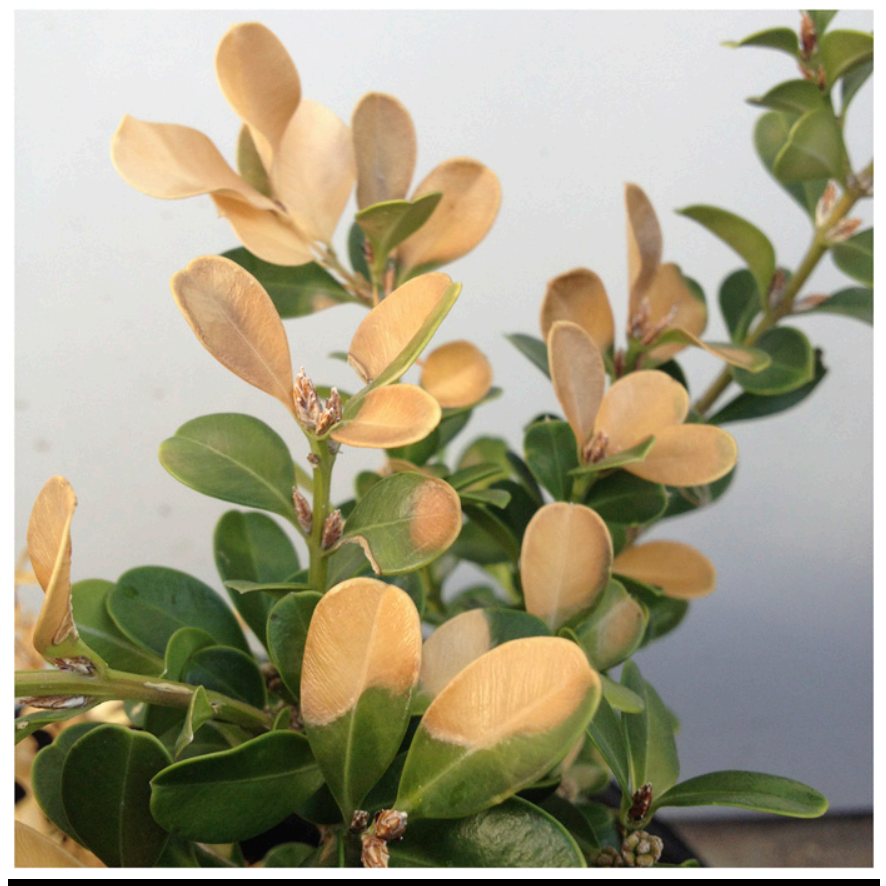

FIGURE 21

Foliar symptoms caused by high temperature in greenhouse.

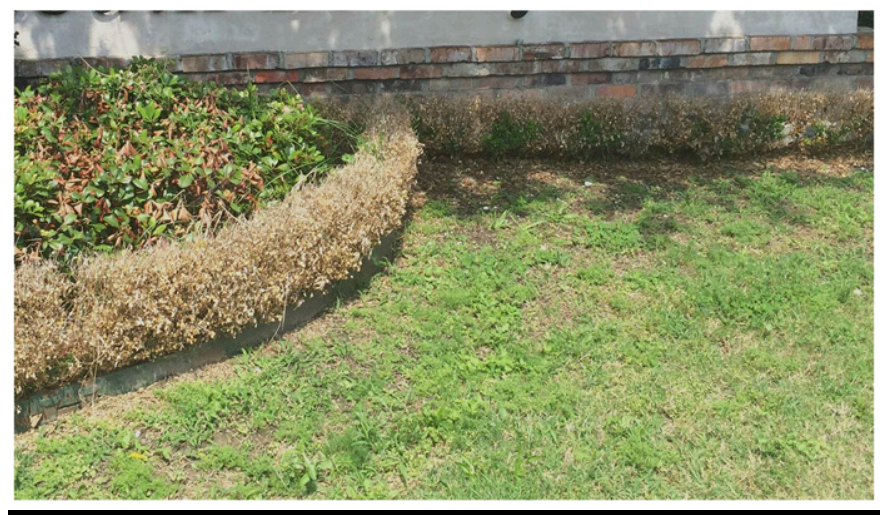

FIGURE 22

Foliar symptoms caused by herbicide injury. 


\section{Acknowledgments}

The authors would like to thank Dr. Mike Munster of North Carolina State University for reviewing the manuscript. We would also like to thank Ms. Mary Ann Hansen of Virginia Tech University for photo of cold injury on boxwood, Mr. V. L. Smith of the Connecticut Agricultural Experiment Station for photo of boxwood blight, and Dr. Cassie Kooner and Mr. John Olive of Auburn University for photo of boxwood dieback in boxwood liners.

\section{Literature Cited}

Crouch, J. 2012. Colletotrichum fungal pathogens and symbionts of ornamental nursery and landscape plants. Phytopathology 102:S4.26-S4.27.

Doyle, V. P., Oudemans, P. V., Rehner, S. A., and Litt, A. 2013. Habitat and host indicate lineage identity in Colletotrichum gloeosporioides $\mathrm{s}$. 1. from wild and agricultural landscapes in North America. PLoS One 8:e62394.
Farr, D. F., and Rossman, A. Y. Fungal databases. Systematic Mycology and Microbiology Laboratory, ARS, USDA. Retrieved August 12, 2016, from https://nt.ars-grin.gov/fungaldatabases/

Holcomb, G. E. 1967. Pathogenicity of a Colletotrichum sp. isolated from boxwood. Phytopathology 57:461.

Rojas, E. I., Rehner, S. A., Samuels, G. J., Van Bael, S. A., Herre, E. A., Cannon, P., Chen, R., Pang, J., Wang, R., Zhang, Y., Peng, Y. Q., and Sha, T. 2010. Colletotrichum gloeosporioides s.l. associated with Theobroma cacao and other plants in Panamá: Multilocus phylogenies distinguish host-associated pathogens from asymptomatic endophytes. Mycologia 102:1318-1338.

Singh, R., Graney, L., and Williamson, M. 2015. First report of boxwood dieback caused by Colletotrichum theobromicola in the United States. Plant Dis. 99:1274

Singh, R., and Ratcliff, S. 2016. Boxwood dieback. National Pest Alert, North Central IPM Center. Available at: http://www.ncipmc.org/action/alerts/ boxwood.php

Weir, B. S., Johnston, P. R., and Damm, U. 2012. The Colletotrichum gloeosporioides species complex. Stud. Mycol. 73:115-180. 